www.jmscr.igmpublication.org

Impact Factor 5.84

Index Copernicus Value: 83.27

ISSN (e)-2347-176x ISSN (p) 2455-0450

crossref DOI:_https://dx.doi.org/10.18535/jmscr/v5i5.57

Journal Of Medical Science And Clinical Research

\title{
Prevalence of Hypertension among Adults Attending A Tertiary Care
} Centre

\section{Authors \\ Dr Beena Unnikrishnan ${ }^{1}$, Dr Krishnan Kutty ${ }^{2}$, Dr Mookambika R .V Dr Vishnu G Ashok ${ }^{4}$}

${ }^{1,2}$ Associate Professor Department of General Medicine Sree Mookambika Institute of Medical Sciences , Kulasekharam, Tamilnadu India

${ }^{3}$ Assistant Professor Department of General Medicine SreeMookambika Institute of Medical Sciences , Kulasekharam, Tamilnadu India

${ }^{4}$ Assistant Professor Department of Community Medicine SreeMookambika Institute of Medical Sciences Kulasekharam, Tamilnadu India Email: vishnusastha@gmail.com

\section{ABSTRACT}

Background: The burden of the chronic Non-Communicable Diseases (NCD), especially heart disease, stroke, hypertension, diabetes, cancer and chronic respiratory disease, is increasing in the low and the middle-income countries. Hypertension is a emerging as a major public health problem. It is an established major risk factor and a leading cause of cardiovascular diseases worldwide. Some 600 million people worldwide have high blood pressure and nearly 3 million die every year as a direct result.

Aims \&Objectives: To find out the prevalence of hypertension among adult patients attending a tertiary care centre

Subjects and Methods: A Cross sectional study was carried out in the outpatient department of a tertiary care Centre. All the adults who were aged 18 years and above, who attended the Outpatient Department of General Medicine for master health check up were included. Participants who already on anti hypertensive treatment were excluded

Results: Out of the 100 study participants $60 \%$ were males. $30 \%$ of the study participants were found to be pre hypertensive while 10\% and 12\% of the respondents where in the stages I and II of hypertension. Over all 22\% of the study participants are found to be hypertensive.

Conclusion: This study highlights the importance of screening as a tool for early detection of unknown hypertension among adults

Keywords: Hypertension, Prevalence ,Pre Hypertension.

\section{INTRODUCTION}

The burden of the chronic Non-Communicable Diseases (NCD), especially heart disease, stroke, hypertension, diabetes, cancer and chronic respiratory disease, is increasing in the low and the middle-income countries ${ }^{1}$. Hypertension is a emerging as a major public health problem .It is an established major risk factor and a leading cause of cardiovascular diseases worldwide.Some 600 million people worldwide have high blood 
pressure and nearly 3 million die every year as a direct result. Yet seven out of every 10 people with hypertension are not being treated adequately, according to WHO and the International Society of Hypertension (ISH) ${ }^{2}$. The prevalence pattern of hypertension in developing countries is different from that in the developed countries. In India, a very large, populous and typical developing country, community surveys have documented that between three and six decades, prevalence of hypertension has increased by about 30 times among urban dwellers and by about 10 times among the rural inhabitants. Various factors might have contributed to this rising trend and among others, consequences of urbanization such as change in life style pattern, diet and stress, increased population and shrinking employment have been implicated.Various hypotheses have been put forward to explain this rising trend and among these, consequences of urbanization such as change in life style pattern, diet and stress have been implicated. The current urbanization rate in India is $35 \%$ as compared to $15 \%$ in the 1950 . With growing urbanization, socio-developmental changes have taken place over last 40-50 years. Dramatic changes in life style from traditional to modern have lead to physical inactivity due to technological advances. Rising affluence has modified the dietary pattern characterized by increased consumption of diets rich in fat, sugar and calories. Furthermore, increasing population growth at the current rate of about $2 \%$ in each year and technological advances have shrunken the employment opportunities particularly among young generation - leading to stress and hypertension in young persons, including students and laborers ${ }^{3,4,5}$.Various review literatures showed that the percentages of the awareness , treatment and control of hypertension are low in the Indian adult population ${ }^{6,7,8,9}$.The present study was undertaken to provide the data on the prevalence of hypertension among adults aged 18 years and above who attended the outpatient department of a tertiary care centre

\section{AIMS \& OBJECTIVES}

To find out the prevalence of hypertension among adult patients attending a tertiary care centre.

\section{MATERIALS AND METHODS}

Study design: Cross sectional Study

Study setting: Outpatient department of General Medicine Sree Mookambika Institute of Medical Science, Kulasekharam.

Approximate total duration of the study: 2 months (January 2016-march 2016)

Detailed description of the groups: Adults of both sexes attending general medicine department for master health check up

Total sample size of the study: 100

Scientific basis of sample size used in the study: Adults of both sexes attending master health checkup for the period of two months so no sample size

Inclusion criteria: All the adults who were aged 18 years and above, who attended the Outpatient Department of General Medicine were included.

Exclusion Criteria: Participants who already on anti hypertensive treatment

All the participants who were aged less than 18 years of age. The patients who were non cooperative and those who refused to provide the necessary information were also excluded.

Methods(s)/Technique(s)/Reagent(s)/Kit(s) etc. used to measure the qualitative parameters along with their manufacturing source details: Structured, pretested schedule was used to collect the data with regards to the socio-demographic characteristics (age, gender, religion and the socioeconomic status) and the blood pressure pattern. The modified BG Prasad's classification was applied to measure the individual's socioeconomic status ${ }^{10}$

Procedure: After getting approval from Institutional Human Ethical Committee written informed consent was obtained from the participants before enrolling them into study. Pretested questionnaire was applied by the chief investigator. Two measurements of the blood pressure of each study participant were made 30 
minutes apart, with the participants in the sitting position, by using a mercury column sphygmomanometer. The blood pressure measurements were made on the subject's left arm by using a cuff of the appropriate size, at the level of the heart. The cuff pressure was inflated $30 \mathrm{~mm} \mathrm{Hg}$ above the level at which the radial pulse disappeared and then it was deflated slowly at the rate of about $2 \mathrm{~mm}$ per sec. The readings were recorded to the nearest $2 \mathrm{~mm} \mathrm{Hg}$.In the cases where the two readings differed by over $10 \mathrm{~mm}$ of $\mathrm{Hg}$, a third reading was obtained, and the three measurements were averaged. The pressures at which the sound appeared and disappeared, were taken as the Systolic Blood Pressure (SBP) and the Diastolic Blood Pressure (DBP) respectively. The blood pressure was graded according to US Seventh Joint National Committee on the Detection, Evaluation and the Treatment of Hypertension (JNC VII) criteria ${ }^{5}$.Hypertension was diagnosed when the systolic BP was $\geq$ $140 \mathrm{mmHg}$ and/or the mean diastolic BP was $\geq$ $90 \mathrm{mmHg}$, or when a person had a history of an anti hypertensive treatment, fifteen days before the survey was done. Isolated systolic hypertension was defined as a systolic BP of $\geq 140 \mathrm{mmHg}$ and a diastolic BP of $<90 \mathrm{mmHg}$

Data collection and Statistical Analysis:Data collected was entered in Microsoft Excel spread sheet and analysis was done using SPSS version 20. Results were expressed as mean \pm SD. Descriptive statistics was used for analysis

\section{RESULTS}

A cross sectional study was conducted on hypertension among adults of both sexes aged 18 and above in a tertiary care centre. A total of 100 participants were studied and the observation as follows. Out of the 100 study participants $60 \%$ were males.Most of the adults belonged to nuclear families (50\%) followed by joint family (35\%). There was no illiterate in the study participants. Most of the adults belonged to high school(46\%). According to BG Prasad classification most of the adults belongs to upper lower class (52.8\%). 30\% of the study participants were found to be pre hypertensive while $10 \%$ and $12 \%$ of the respondents where in the stages I and II of hypertension. Over all $22 \%$ of the study participants are found to be hypertensive. Over all the mean blood pressure were $132 \pm 19 / 79 \pm 14$ $\mathrm{mm} \mathrm{Hg}$. The proportion of hypertension showed an increase in trend with age. 7 (17\%) of the 40 who were aged between 18-30 years were found to be hypertensive, while $10(40 \%)$ of the 25 individuals who were aged above 60 years were found to be hypertensive. The proportion of hypertension was higher among females (55.2\%) as compared to males (44.8\%).Although a higher proportion of respondents (14\%) with a smoking habit were found hypertensive as compared to those who did not smoke (7\%).

\section{DISCUSSION}

The prevalence of hypertension has risen from 5$15 \%$ in 1960 s to $20-36 \%$ in the past 10 years $^{11,12}$. Rapid urbanization, un health dietary practices, behavioral changes and increased life expectancy are attributed for this alarming rise in blood pressure. The high prevalence of hypertension $(22 \%)$ in the current study, confirmed this increasing trend. A study done by Santhoshkumar et $\mathrm{al}^{13}$ showed a low prevalence of $13 \%$.A high prevalence of hypertension was reported (46\%) in a study which was conducted among the outdoor patients of an urban health centre of Kolkata ${ }^{14}$. The proportion of hypertension, as well as the mean systolic and diastolic blood pressures, were found to increase steadily with an increase in age. These findings were similar which had been reported in the studies done by Gupta et $\mathrm{al}^{15}$ and Yadav etal ${ }^{16}$. Such changes of blood pressure with age, might be due to the changes in the vascular system. The proportion of hypertension was slightly higher among females $(55.2 \%)$ as compared to that in males $(44.8 \%)$. similar observations was done by Gupta et all in Mumbai. A female preponderance was also observed by Kabiret $\mathrm{al}^{17}$. A higher proportion of hypertension was found among the upper socioeconomic status. 


\section{LIMITATIONS}

Blood pressure pattern estimates were based on the measurements of the blood pressure on a single day and were not repeated again for practical reasons.

\section{CONCLUSION}

This study highlights the importance of screening as a tool for early detection of unknown hypertension among adults

\section{REFERENCES}

1. World Health Organization. Preventing chronic diseases-a vital investment. Geneva: World Health Organization; 2005.

2. World Health Organization, International Society of Hypertension Writing Group. 2003 World Health Organization (WHO)/International Society of Hypertension (ISH) statement on management of hypertension. Journal of hypertension. 2003 Nov 1;21(11):1983-92.

3. Hypertension study group. Prevalence, awareness, treatment and control of hypertension among the elderly in Bangladesh and India: a multicentre study. Bull World Health Organ. 2001 ;79:490-500

4. Gupta R. Meta analysis of prevalence of hypertension in India. Indian Heart Journal. 1997 ;49:43-48

5. Chobanian AV, Bakris GL, Black HR, Cushman WC, Green LA, IzzoJr JL, Jones DW, Materson BJ, Oparil S, Wright Jr JT, Roccella EJ. The seventh report of the joint national committee on prevention, detection, evaluation, and treatment of high blood pressure: the JNC 7 report. Jama. 2003 May 21;289(19):2560-71

6. Quasem I, Shetye MS, Alex SC, Nag AK, Sarma PS, Thankappan KR, et al . Hypertension Study Group. Prevalence, awareness, treatment and control of hypertension among elderly in Bangladesh and India: a multicentric study. Bulletin of the World Health Organization 2001;79(6):490-500.

7. Bharucha NE, Kuruvilla T. Hypertension in the Parsi community of Bombay: A study on prevalence, awareness and compliance to treatment. BMC Public Health. 2003;3:1-5.

8. Deshmukh PR, Gupta SS, Bharambe MS, Maliye C, Kaur S, Garg BS. Prevalence of hypertension, its correlates and levels of awareness in rural Wardha, Central India. Journal of Health \& Population in Developing Countries. 2005;1-12.

9. Mohan V, Deepa M, Farooq S, Datta M, Deepa R. Prevalence, awareness and control of hypertension in Chennai - The Chennai Urban, and treatment of high blood pressure- The JNC 7 report.JAMA. $2003 ; 289: 2560-2572$

10. Prasad BG, Biswas KK, Gupta SK. Region-based image retrieval using integrated color, shape, and location index. computer vision and image understanding. 2004 Jun 30;94(1):193-233.

11. Gupta R. Meta-analysis of prevalence of hypertension in India. Indian Heart J.1997; 49: 43-48.

12. .Mohan V, Deepa M, Farooq S, Datta M, Deepa R. Prevalence, Awareness and Control of Hypertension in Chennai - The Chennai Urban Rural Epidemiology Study (CURES - 52). JAPI. 2007; 55: 326-32.

13. Singh AK. Prevalence of Hypertension and its epidemiological correlates-A cross sectional study among patients attending outpatient department of urban health center Srinagar Garhwal.National Journal of Research in Community Medicine.. 2014 3(4):343-50

14. Soumya Deb, AparajitaDasgupta. A Study on Risk Factors of Cardiovascular Diseases in an Urban Health Center of Kolkata. Indian Journal of Community Medicine. 2008; 33 (4): 275. 
15. Gupta PC, Gupta R, Pednekar MS. Hypertension prevalence and blood pressure trends in 88653 subjects in Mumbai, India. Journal of Human Hypertension. 2004; 18:907-10.

16. Yadav S, Boddula R, Genitta G, Bhatia V, Bansal B, Kongara S. Prevalence and risk factors of pre-hypertension \& hypertension in an affluent north Indian population. Indian J Med Res. 2008; 128: 712-20

17. A Kabir, TK Barman, NA Yousuf, N Fatima, J Banik. Prevalence of Hypertension among the Patients whoattend medicine outdoor of Dhaka Medical College Hospital. J Medicine. 2007;8:4952. 